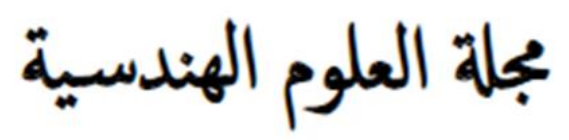

\title{
Performance of concrete columns reinforced partially with Basalt fiber rebars and steel under cyclic loading
}

\author{
Adam Ishag Ibrahim ${ }^{1, *}$ \\ 1 Civil Engineering Department, Blue Nile University, Kosti, Sudan \\ * Corresponding author: Adam Ishag Ibrahim (e-mail: adamishag@yahoo.com).
}

Article history: Received 06 June 2020, Received in revised form 4 November 2020, Accepted 11 November 2020

\begin{abstract}
This paper presents numerical and experimental results of concrete columns reinforced longitudinally with basalt fiber reinforced polymer (BFRP) and steel bars as a composite system. The main objective is to reduce the number of steel bars replacing by BFRP bars under cyclic loading using open system for earthquake engineering (OpenSees). Moreover, to achieve the goal of this study, the parameter relationship of this system was measured in five bridge columns. One column was referred as a reference, and the other three with $17 \%, 33 \%$ and $50 \%$ of BFRP with steel amount of $83 \% 67 \%$ and $50 \%$ respectively was studied. Moreover, the main parameter was analyzed is the energy dissipation amount, hysteretic performance and residual displacements. The columns reinforced with BFRP were given the significant results in the studied parameters especially the columns reinforced with a high percent of BFRP compare to steel columns.
\end{abstract}

Keywords: Concrete column, basalt fiber reinforced polymer, residual displacements, hysteretic performance.

\section{INTRODUCTION}

The Basalt rock in Sudan found in Al-Gedaref areas and in Al-Bayuda [1] and Jabal Marra and some other areas in quantities that are not small and can be used in engineering works besides the other structural materials. In recent years, construction iron prices have increased significantly, which led to the reluctance of owners of small buildings in rural areas to use it and replace it with beams made of wood, so it was necessary to find cheap alternative solutions that work alongside steel without structural problems occurring. The failure of contemporary buildings of this type reveals the inadequacy of existing design methods and code regulations for near-fault pulse-type ground motions and non-ductile designs [2]. This study focused on strengthening RC columns with BFRP rebars replacing the ordinary steel rebar and exposed to minor or moderate earthquakes. Recently, FRP composites have been used widely in concrete structures as internal reinforcing bars and external confinement sheets, for example.
However, FRP bars didn't used widely in concrete structures in the place of traditional steel bars because research in this field is still ongoing, and the standard ACI 440.1R-06 [3] commends that further research in this area be should be conducted. In particular, the behavior of the compressive strength of FRP rebar in reinforced concrete has not been studied adequately. Ibrahim et al. has conducted test in concrete column reinforced longitudinally with hybrid rebar (Steel and BFRP) and they found significant results in this field $[4,5]$. Also the strength and behavior of concrete columns reinforced with carbon fiber-reinforced polymer bars and spirals (CFRP) with glass fiber-reinforced polymer (GFRP) hoops have been studied, and they reported that the small closely spaced of CFRP and GFRP spirals increase the strength and ductility Afifi, Mohamed and Benmokrane [6], Mohamed, Afifi and Benmokrane [7]. In addition, United States and Canada several projects has been conducted using FRP rebar in place of epoxy-coated steel bars to reinforce bridge decks [8]. Moreover, the columns reinforced with 
Aramid fiber-reinforced polymer (AFRP) bars under a combination of compression and tension force was conducted by Kawaguchi Kawaguchi [9]. Add to that the square concrete columns reinforced with GFRP rebars longitudinally and transversely under axial loads had been studied by Hany Hany Tobbi and Brahim [10]. In addition, they reported that the GFRP bars it can be used in concrete compression members if the confinement is sufficient to prevent the bars from buckling. Therefore, FRP materials offer an excellent alternative to steel reinforcement because of their good mechanical properties and speed in repair and ease of installation.

Recently, basalt fiber-reinforced polymers (BFRP) has been used to reinforce concrete structures. BFRP has the characteristics of high-tensile strength, durability, temperature resistance, and chemical resistance [11]. Moreover, Experimental and theoretical studies of RC columns reinforced with BFRP rebars have been conducted, and established that large diameters of BFRP has increases the ultimate displacement with the corresponding peak loads, initial and post-yield stiffness's, and ductility [12, 13]. Consequently, BFRP was selected for use in this study because of the aforementioned distinctive characteristics, and their large quantity existing in Sudan. The mechanical and material properties of this study as shown in table 1 .

\section{RESEARCH SIGNIFICANCE}

This study aimed to evaluate the seismic performance of RC columns reinforced with Steel and BFRP bars. An experimental study was conducted to evaluate the replacement of the ordinary reinforcements with the BFRP (But some results did not available in this paper due to copyright agreement with the other journals). Two columns were reinforced with steel bars and hoop set as a reference (test, simulation). The last three columns were reinforced with proposed hybrid types of reinforcement, and the ratio between steel and BFRP bars was a designed as study parameter and the values were examined is (17\%, 33\%, and 50\%). The residual displacement, energy dissipation, stiffness degradation, and damping ratio was measured and compared with columns test results.
TABLE 1. MECHANICAL AND MATERIAL PROPERTIES.

\begin{tabular}{lccccc}
\hline Bar type & $\begin{array}{c}\boldsymbol{D} \\
(\mathbf{m m})\end{array}$ & $\begin{array}{c}\boldsymbol{E}_{I} \\
(\mathbf{G P a})\end{array}$ & $\begin{array}{c}f_{y} \\
(\mathbf{M P a})\end{array}$ & $\begin{array}{c}f_{u} \\
(\mathbf{M P a})\end{array}$ & $\begin{array}{c}\mathcal{E}_{u} \\
(\boldsymbol{\%})\end{array}$ \\
\hline Steel & 12 & 210.0 & 644.6 & 735.9 & 10.0 \\
Steel & 6.0 & 210.0 & 300.0 & 420.0 & 13.43 \\
BFRP bar & 10 & 66.83 & - & 1697.0 & 11.76 \\
Basalt fiber & 0.013 & 90 & - & - & 2.50 \\
Resin & - & 3.60 & - & - & 6.10 \\
\hline \hline
\end{tabular}

\section{SPECIMENS DETAIL}

Four circular cantilever RC columns was constructed and under cyclic lateral loading with constant axial loading. All the column was the same dimensions of $1000 \mathrm{~mm}$ high and $300 \mathrm{~mm}$ in diameter with an aspect ratio of 3.33 and a clear concrete cover that was $20 \mathrm{~mm}$ in size (Fig. 1). One sample (12STC) was designed as a control column reinforced with normal steel bars.

Twelve D12 (Ø12 mm) steel bars were used as longitudinal reinforcement, steel ratio of $\rho_{l}=0.0192$, as shown in Table 2 and Fig. 1. Moreover, $6 \mathrm{~mm}$ diameter circular steel hoops with space $40 \mathrm{~mm}$ were used in the plastic hinge zone and $60 \mathrm{~mm}$ at above it [14].

The other three RC specimens were reinforced with BFRP as shown in fig.

TABLE 2. REINFORCEMENT DETAIL.

\begin{tabular}{llll}
\hline \hline Design concept & Labels & \multicolumn{2}{l}{ Longitudinal reinforcement } \\
\cline { 3 - 4 } & & Type & $\begin{array}{l}\text { Ratio } \\
\text { (\%) }\end{array}$ \\
\hline Control & 12STC & ordinary & $12 \varnothing 12(1.92)$ \\
Control simulation & 12STS & ordinary & $12 \varnothing 12(1.92)$ \\
BFRP columns & 2BFRP & 2BFRP-10ST & $12 \varnothing 12(1.92)$ \\
& 4 BFRP & 4BFRP-8ST & $12 \varnothing 12(1.92)$ \\
& 6BFRP & 6BFRP-6ST & $12 \varnothing 12(1.92)$ \\
\hline \hline
\end{tabular}

\section{MATERIAL PROPERTIES}

The strength of the steel rebars was determined by testing three specimens with each diameter in accordance with the 2014 ASTM [15]. The results were shown in table 1.

\section{TEST SETUP}

All the columns were subjected to axial and lateral cyclic loads (push-over). A hydraulic jack with a capacity of $1000 \mathrm{kN}$ was used to apply the axial load until the until the end of test. The constant axial force 365 was applied on surface of the column's cap, which was $12 \%$ of the concrete's axial compression ratio Fig.3. 


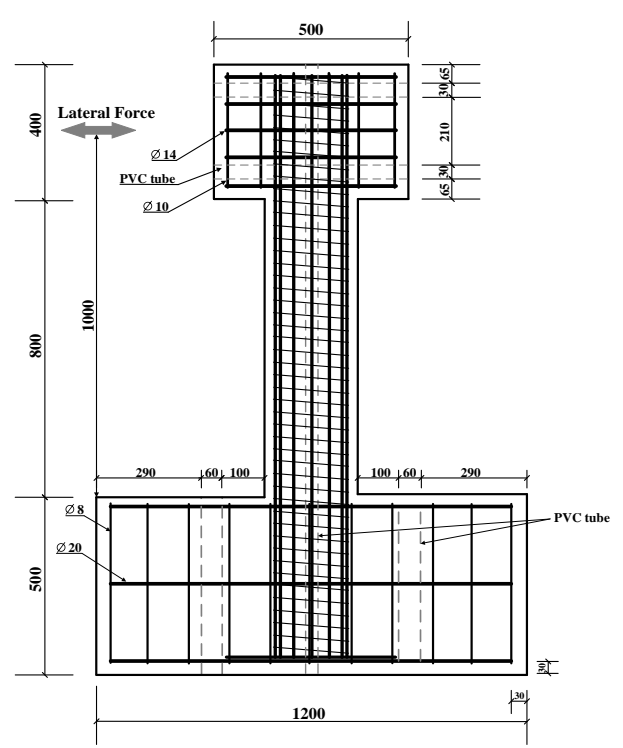

Fig. 1. Reinforcement details of test specimens. (Note: units in $\mathrm{mm}$ ).

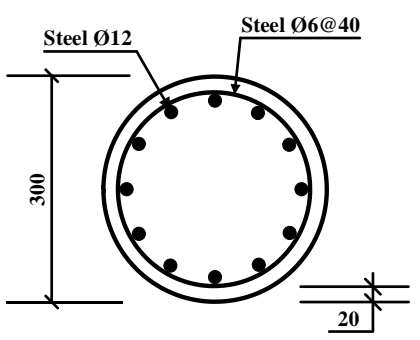

(a)

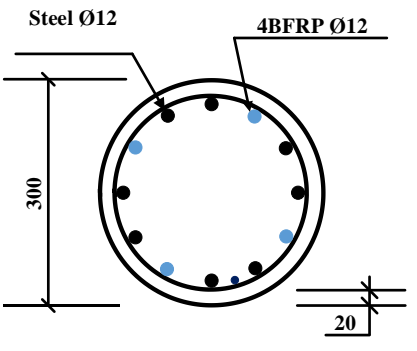

(c)

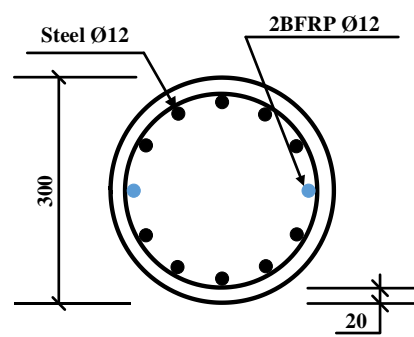

(b)

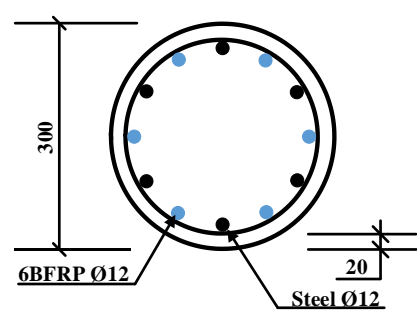

(d)
Fig. 2. Cross sections and reinforcement details of specimens: (a) 12STC; (b) 2BFRP; (c) 4BFRP; and (d) 6BFRP (Note: units in mm).

Furthermore, the lateral cyclic load was applied using an actuator mounted on the wall frame. The column's footing was fixed to a strong base and wall frame to minimize the sliding of the column's base and rigid body movement in response to the cyclic loading. Adding to that, the column was equipped with the load cells, strains gauge, linear variable displacement transformers (LVDTs) and transducer sensors devices to measure displacements with corresponding loads as shown in Fig. 3.

\section{LOADING PATTERN}

Firstly, apply the axial load and kept constant until the end of the test. Second, the lateral cyclic load controlled by a force and started with $\pm 10 \mathrm{kN}$ upward increased by $\pm 10 \mathrm{kN}$ at each step until the column yielded. After the specimen yielded, the program continued with displacement control (yield deformation value) repeating each step three times until up end, as shown in Fig. 3.
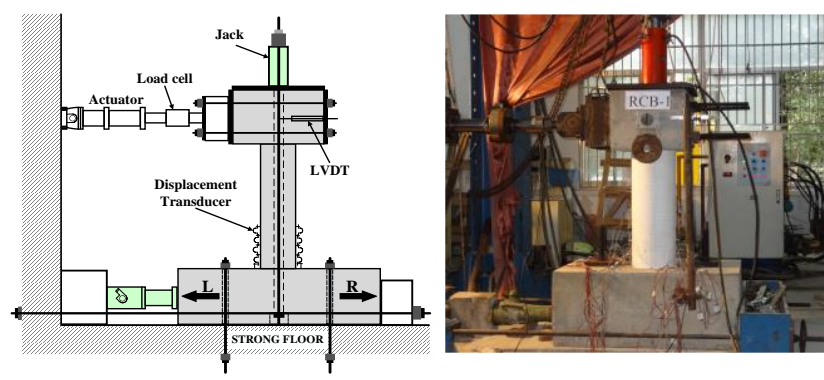

Fig. 3. Test setup.

7.

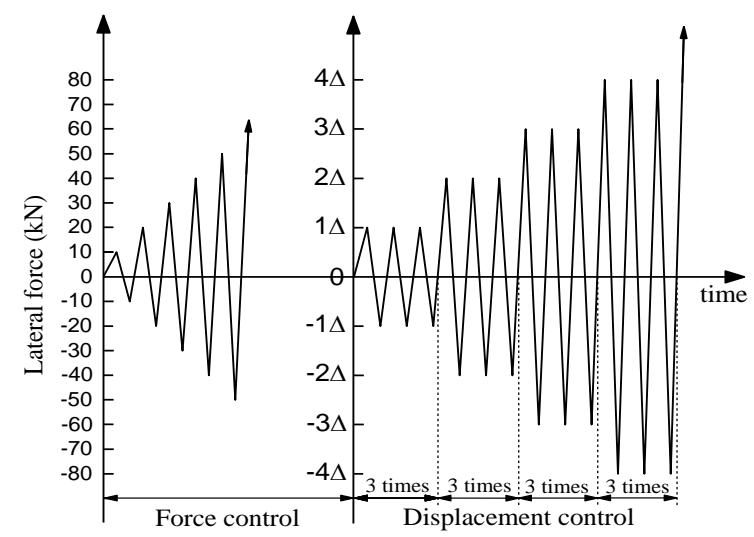

Fig. 4. Lateral force-displacement history.

\section{RESULTS}

\section{A. Hysteretic Behavior and Loops}

The influence of the reinforcing BFRP and steel on the hysteretic loop, energy dissipation capacity, and stiffness of each column was investigated using the test results. The hysteretic force displacement responses collected during the tests was shown in Figs. 5 (graph05). In addition, the strength of proposed specimens was calculated using an open system for earthquake engineering simulations (OpenSees) [16] , and the results were presented with the result of the test in the same figure. Fig. 5 (a) to (e) shows that the hysteretic force-displacement and cyclic load capacity of all specimen. The results for specimens 2BFRP, 4BFRP and 6BFRP show that the hysteresis loops were more comprehensive due to stiffness of BFRP. Moreover, these figures showed columns had more capacity to carry cyclic loads, which was accompanied by a significant drop in the residual displacement, as shown in specimen 
6BFRP and 4BFRP Therefore, BFRP has showed influences on the residual displacements when used to reinforce concrete columns. Consequently, the hysteresis behaviors of simulated specimens varied from each other according to the amount of BFRP.

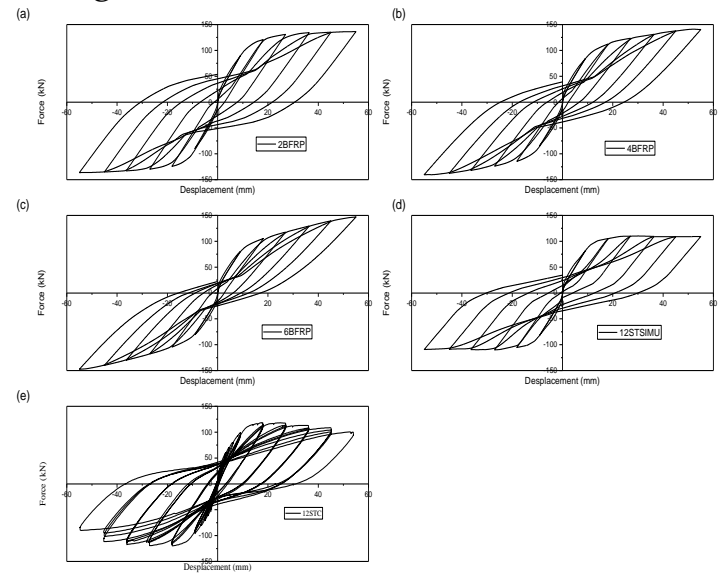

Fig. 5. Hysteretic force-displacement curve of all specimen.

\section{B. Residual Deformations of Bridge Columns}

The residual displacement response was defined according to Japanese code [17]. The residual displacements of specimens BFRP specimens less than control specimen by $15.7 \%, 28.6 \%$ and $48.6 \%$. However, the specimen 2BFRP exhibited good residual performance $(30 \mathrm{~mm})$ because of the elasticity of the BFRP, which contributed to the decrease in the residual deformation at large drifts.

\section{A. The Envelope Curve}

The envelope curve for the load versus the displacement of the specimens was obtained from summation of maximum values on each axis $(X$, Y) for each force cycle divided by two of the hysteretic loops, as presented in Fig. 7. From this figure, the specimens $2 \mathrm{BFRP}, 4 \mathrm{BFRP}$, and 6BFRP showed a high response for force-displacement capacity.

\section{A. Energy Dissipation, Viscous Damping and Stiffness Degradation}

All the structural exposed to earthquakes should be designed to dissipate energy from dynamic forces through their responses, are desirable. Therefore, the quantify the energy dissipated when the column is subjected to a time-varying force by calculating the area of hysteresis loops using Equation 1, as shown in Fig. 8.

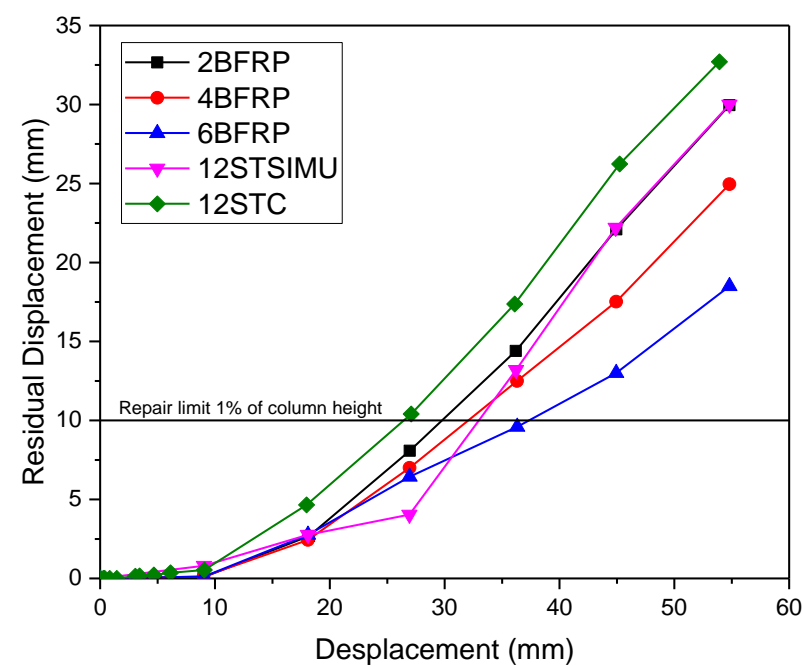

Fig. 6. Residual displacement response of the specimens.

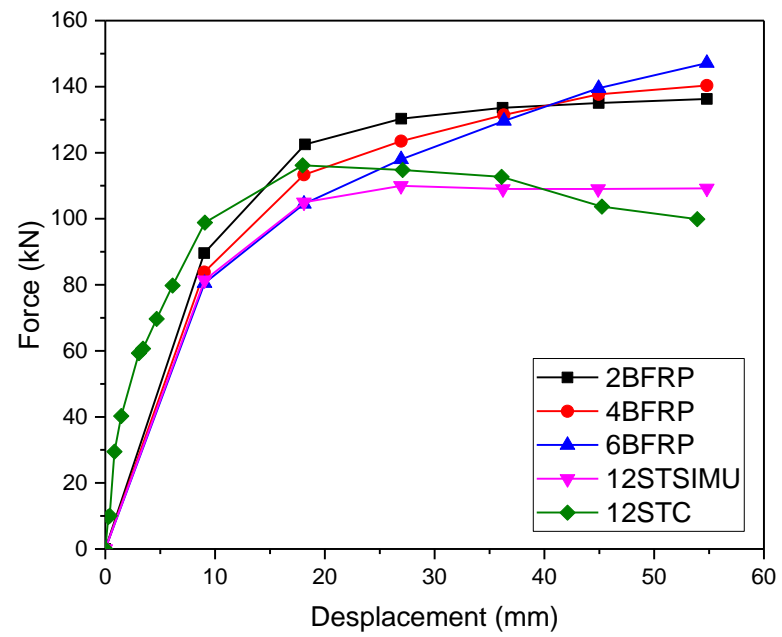

Fig. 7. Envelop and ideal curves definitions.

In addition, the equivalent viscous damping ratio $\left(\xi_{\text {eq }}\right)$ is a significant element of the seismic analysis methods that must be used to assess the capacity of a material to dissipate energy. The equivalent viscous damping ratio for specimens was calculated by the ratio of the measured cyclic area to the elastic-plastic area as shown in Fig. 8 following the process proposed by Chopra and Priestley [18, 19]. Moreover, the energy dissipation and damping ratios was calculated using Equations 1 and 4.

$\left(E_{e}\right)_{i}=\frac{\left(P_{m}\right)_{i}\left(\Delta_{\max }\right)_{i}}{2}$

where $\left(E_{e}\right)_{i}$ is the dissipated energy stored by an equivalent linear system, which is given by the area of the load vs. displacement curve obtained from the cyclic loops; $\left(P_{m}\right)_{i}$ and $\left(\Delta_{\max }\right)_{i}$ are the absolute values of the average maximum load and displacement for each cycle; they are given by 
$\left(P_{\mathrm{m}}\right)_{i}=\frac{\left|\left(P_{i+1}\right)\right|+\left|\left(P_{i-1}\right)\right|}{2}$

$\left(\Delta_{\max }\right)_{i}=\frac{\Delta_{i+1}+\Delta_{i-1}}{2}$

where $P_{i+1}$ and $P_{i-1}$ are the maximum and minimum values of the load in cycle $i$ cycle; and $\Delta_{i}$ is maximum displacement in cycle $i$.

$\xi_{e q}=\frac{\left(E_{D}\right)_{i}}{4 \pi\left(E_{e}\right)_{i}} \%$

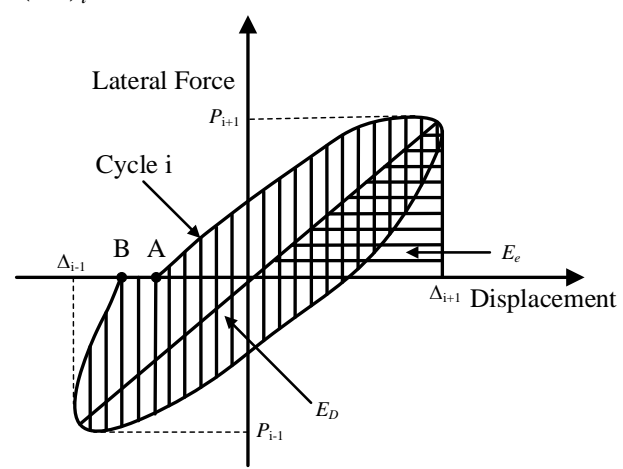

Fig. 8. Analytical curve for equivalent viscous damping and energy dissipated.

where $\xi_{e q}$ is the damping ratio and $\left(E_{D}\right)_{i}$ is the amount of energy dissipated in cycle $i$ according to the hysteresis loops.

To determine the energy dissipation of all the specimens, Equation 1 was used with the data obtained in the test, and the results showed that the energy of a specimen 12STC was greater than that of the specimens reinforced with BFRP. As shows in Fig. 9 the specimen 2BFRP dissipated the second-largest of energy. In addition, the BFRP rebars makes the initial stiffness is the same with column reinforced with steel bars after $8 \mathrm{~mm}$ displacement illustrated in Fig. 10.

The equivalent viscous damping ratio is illustrated in Fig. 11. This figure shows that the BFRP significantly affected the viscous damping, and the results indicate that the specimens reinforced with BFRP exhibited results little deferent to 12STC but it's similar to simulated control specimen up end of curve as shown I fig. 11. But in case of specimen 6BFRP (amount of BFRP equal to steel) it shows initial results same to control up $8 \%$ and then the specimen curve dropped down due to BFRP began to rupture, which caused the specimens lose their viscous damping ability more than 12STC.

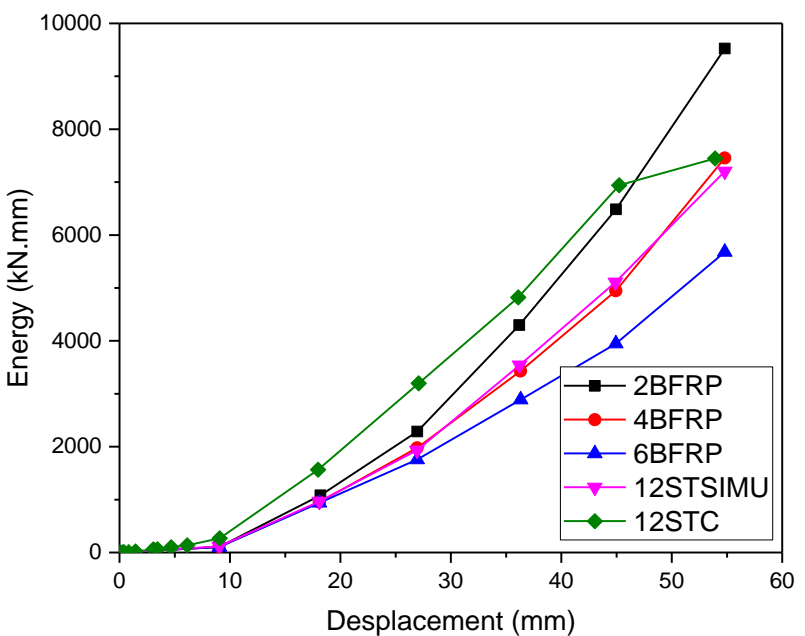

Fig. 9. Cumulative dissipated energy absorption versus drift ratio.

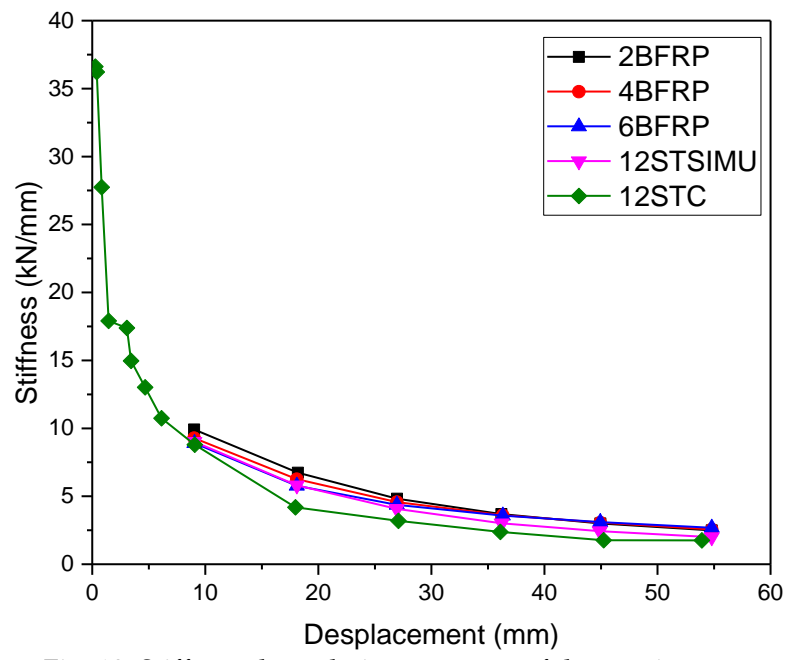

Fig. 10. Stiffness degradation response of the specimens.

\section{CONCLUSION}

This study aimed to investigate the performance of concrete columns reinforced with BFRP bars replacing part of traditional steel rebars under the effect of axial and cyclic force, that to reduce the cost of steel by using this local product. Finally, the following conclusions of the study can be drawn:

[1]. The column reinforced with the 4BFRP, 6BFRP bars exhibited a large ability to carry lateral cyclic force.

[2]. The BFRP fiber reduced the columns' residual deformation of specimens 2BFRP, 4BFRP, and 6BFRP; Also, that makes the initial stiffness is the same with column reinforced with steel bars after $8 \mathrm{~mm}$ displacement.

[3]. Compared to the conventional column reinforced with steel, the columns that were reinforced with BFRP maintained stable cumulative amounts of viscous damping ratios and dissipated energy. 


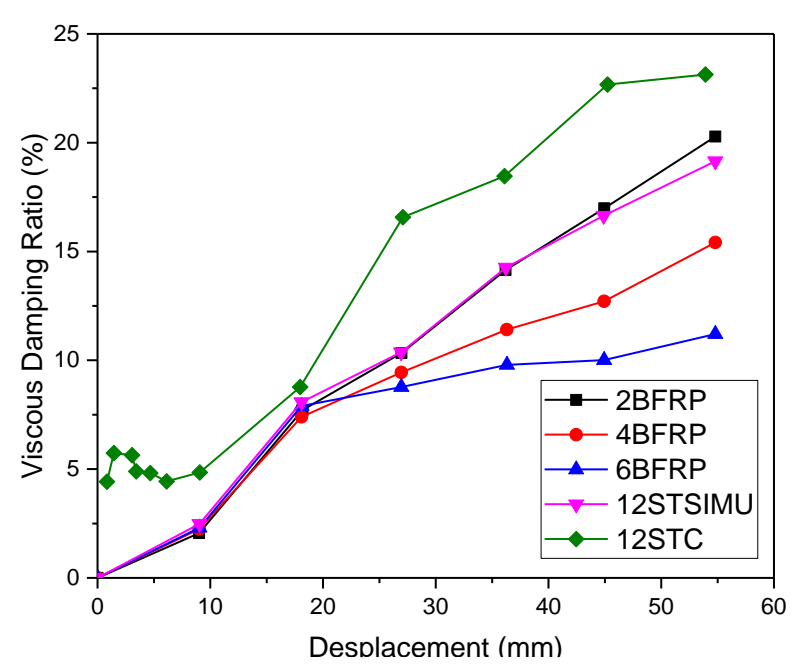

Fig. 11. Equivalent Viscous Damping Ratio of the specimens.

\section{REFERENCES}

[1]D. C. Almond, O. M. Kheir, and S. Poole, "Alkaline basalt volcanism in northeastern Sudan: a comparison of the Bayuda and Gedaref areas," Journal of African Earth Sciences (1983), vol. 2, no. 3, pp. 233-245, 1984/01/01/, 1984.

[2] A. Eslami, and H. R. Ronagh, "Effect of FRP wrapping in seismic performance of RC buildings with and without special detailing - A case study," Composites Part B: Engineering, vol. 45, no. 1, pp. 1265-1274, Feb, 2013.

[3] ACI, "Guide for the design and construction of structural concrete reinforced with FRP bars," ACI 440.1 R, vol. 6, 2006.

[4] A. I. Ibrahim, G. Wu, Z. Sun, and H. Cui, "Cyclic behavior of concrete columns reinforced with partially unbonded hybrid," Engineering Structures, vol. 131, pp. 311-323, 2017.

[5] A. I. Ibrahim, G. Wu, and Z.-Y. Sun, "Experimental Study of Cyclic Behavior of Concrete Bridge Columns Reinforced by Steel Basalt-Fiber Composite Bars and Hybrid Stirrups," Journal of Composites for Construction, vol. 21, no. 2, pp. 04016091, 2017.

[6] M. Z. Afifi, H. M. Mohamed, and B. Benmokrane, "Strength and Axial Behavior of Circular Concrete Columns Reinforced with CFRP Bars and Spirals," Journal of Composites for Construction, vol. 18, no. 2, pp. 04013035, 2013.

[7] H. M. Mohamed, M. Z. Afifi, and B. Benmokrane, "Performance Evaluation of Concrete Columns Reinforced Longitudinally with FRP Bars and Confined with FRP Hoops and Spirals under Axial Load," Journal of Bridge Engineering, vol. 19, no. 7, pp. 04014020, 2014

[8] B. Benmokrane, E. El-Salakawy, G. Desgagne, and T. Lackey, "FRP bars for bridges," Concrete international, vol. 26, no. 8, pp. 84-90, 2004.

[9] N. Kawaguchi, "Ultimate strength and deformation characteristics of concrete members reinforced with AFRP rods under combined axial tension or compression and bending," Special Publication, vol. 138, pp. 671-684, 1993.

[10] A. S. F. Hany Tobbi, and B. Brahim, "Concrete Columns Reinforced Longitudinally and Transversally with Glass Fiber-Reinforced Polymer Bars," ACI Structural Journal, vol. 109, no. 4, pp. 551, 7/1/2012, 2012.
[11] F. Elgabbas, E. A. Ahmed, and B. Benmokrane, "Experimental Testing of Concrete Bridge-Deck Slabs Reinforced with Basalt-FRP Reinforcing Bars under Concentrated Loads," Journal of Bridge Engineering, pp. 04016029, 2016.

[12] L. Ding, G. Wu, S. Yang, and Z. Wu, "Performance Advancement of RC Columns by Applying Basalt FRP Composites with NSM and Confinement System," Journal of Earthquake and Tsunami, vol. 07, no. 02, pp. 1350007, 2013.

[13] L.-Z. Yao, and G. Wu, "Fiber-Element Modeling for Seismic Performance of Square RC Bridge Columns Retrofitted with NSM BFRP Bars and/or BFRP Sheet Confinement," Journal of Composites for Construction, vol. 0, no. 0, pp. 04016001, 2016.

[14] L. AASHTO, "LRFD bridge design specifications," Washington, DC: American Association of State Highway and Transportation Officials, 2012.

[15] S. ASTM, "A370, 2014,"Standard Test Methods and Definitions for Mechanical Testing of Steel Products," ASTM International, West Conshohocken, PA, 2014, DOI: 10.1520/A0370-14," 2014.

[16] S. Mazzoni, F. McKenne, M. H. Scott, and G. L. Fenves, Open system for earthquake engineering simulation user manual, version 2.0, Univ. of California, Berkeley: Pacific Earthquake Engineering Center, 2009.

[17] JSCE, " Earthquake resistant design codes in Japan, Earthquake Engineering Committee," Japan Society of Civil Engineers (JSCE), 2000.

[18] A. K. Chopra, Dynamics of structures: Theory and Applications to Earthquake Engineering, New Jersey: Prentice Hall 2007.

[19] M. N. Priestley, F. Seible, and G. M. Calvi, Seismic design and retrofit of bridges, New York: John Wiley \& Sons, 1996. 